Dicle University Journal of Engineering (DUJE)

\title{
Orta Karadeniz ve Doğu Karadeniz Bölgesinde kuraklık indisleri üzerine trend analizi uygulanması
}

\author{
Applying trend analysis on drought indices in the Central Black Sea and Eastern \\ Black Sea Region \\ Turgay Partal ${ }^{1 *}$, Ercan Yavuz ${ }^{1}$ \\ ${ }^{1}$ Ondokuz Mayıs Üniversitesi, Mühendislik Fakültesi, İnşaat Mühendisliği Bölümü, Samsun
}

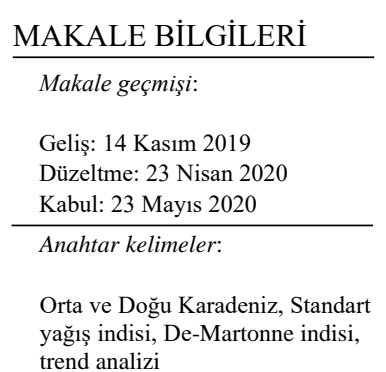

\begin{abstract}
ÖZET
Bu çalışmada Orta Karadeniz ve Doğu Karadeniz Bölgesinde elde edilen kuraklık indisleri üzerine trend analizi yapılmıștır. Trend analizi için ilk önce sıcaklık ve yağıș verileri kullanılarak standart yağıș indisi ve De Martonne indisi elde edilmiştir. Gözlenmiş yağışlar üzerine Mann-Kendall testi uygulanmıştır. Daha sonra Mann-Kendall testi kuraklık indisleri üzerine uygulanmıştır. Çalışmada kullanılan veriler 1960 ve 2015 yılları arasında verilere sahip 12 istasyona aittir. Trend analizine göre yılllı toplam yağışlarda tüm istasyonlar artan eğilim göstermiştir. Aylık yağıșlarda Mart, Eylül ve Ekim aylarında önemli artıș trendleri elde edilmiștir. Standart yağıș indisi için Nemlilik sınıflarında genel olarak artı̧̧ eğilimi vardır. Bunun yanında, yıllık DeMartonne indisinde bazı önemli artan trendler belirlenmiştir.
\end{abstract}

Doi: 10.24012/dumf.646911

\begin{tabular}{|c|c|}
\hline ARTICLE INFO & ABSTRACT \\
\hline $\begin{array}{l}\text { Article history: } \\
\text { Received: } 14 \text { December } 2019 \\
\text { Revised: } 23 \text { April } 2020 \\
\text { Accepted: } 23 \text { May } 2020\end{array}$ & $\begin{array}{l}\text { In this study has been carried out to trend analysis on the drought indices obtained in the Central Black Sea and } \\
\text { Eastern Black Sea Region. Firstly, for trend analysis, the standardized precipitation index and De Martonne index } \\
\text { were obtained using the precipitation and temperature data. Mann-Kendall test was applied on the observed } \\
\text { precipitation data. After then, the Mann-Kendall test was applied on the drought indexes. The data network used } \\
\text { in this study consists of } 12 \text { stations spanning from } 1960 \text { to } 2015 \text {. According to the trend analysis, all of the stations }\end{array}$ \\
\hline $\begin{array}{l}\text { Keywords: } \\
\text { Central and Eastern Black Sea, } \\
\text { Standardized Precipitation }\end{array}$ & $\begin{array}{l}\text { showed increasing trends in the annual total precipitation. For monthly precipitation data, the significant increasing } \\
\text { trends were obtained in March, September and October. For standardized precipitation index, there is generally } \\
\text { an increasing tendency in Wet classifications. Besides, some significant increasing trends were determined in } \\
\text { annual De-Martonne indices. }\end{array}$ \\
\hline
\end{tabular}

Standardized Precipitation

Trend Analysis

\footnotetext{
* Sorumlu yazar / Correspondence

Turgay PARTAL

$\bowtie$ turgay.partal@omu.edu.tr
} 


\section{Giriş}

Kuraklık tüm canlıların yaşamını önemli derecede etkileyen doğal bir çevre olayıdır. Böylesine önemli olan kuraklığın her zaman ve her yerde geçerli olabilecek bir tanımı günümüze kadar yapılamamıştır. Genel olarak kuraklık yağmur veya kar yağışı eksikliği olarak tanımlanmaktadır. Kuraklığın diğer doğal afetlerden farkı, etkisini uzun zamanda ve daha yavaş olarak göstermesidir (Şaylan ve ark., 1997).

Literatürde kuraklık, meteorolojik kuraklık, tarımsal kuraklık, hidrolojik kuraklık ve sosyoekonomik kuraklık olmak üzere dört tip kuraklık tanımlanmaktadır. Kuraklık, meteorolojik kuraklık olarak başlar ve bunu sırasıyla tarımsal kuraklık ve hidrolojik kuraklık takip eder. Meteorolojik kuraklık, bölgenin normale göre daha az yağış alma durumudur (Anisfeld, 2010).

Günümüze kadar kuraklığı takip edebilmek için birçok kuraklık indisi geliştirilmiştir. Yalnızca yağış verilerine ihtiyaç duyması nedeniyle standart yağış indisi (SYİ), hesaplamasının kolay ve güvenli olması nedeniyle tüm dünyada en çok kullanılan kuraklık indisidir (Doğan ve ark., 2012). Yağış indisleri üzerine geçmişte pek çok çalışma yapılmıştır (Keskin ve ark. 2007; Patel ve ark., 2007; Topçuoğlu ve ark. 2008). Bonaccorso ve ark. (2003) Sicilya'da SYİ ile farklı periyotlarda kuraklı analizini araştırmışlar ve seçilen periyotların hassasiyeti etkilediğini belirlemişlerdir. Çaldağ ve ark. (2004), SYİ yöntemi ile Türkiye'nin kuzeybatısı için kuraklık analizi yapmışlardır. Yaptıkları çalışmada, SYİ analizine göre Trakya Bölgesinin (İstanbul hariç) 2000 ve 2001 yıllarında şiddetli kuraklık etkisi altında kaldığını belirlemişlerdir. Selçuk (2017) tez çalışmasında, Kızılırmak havzasında SYİ değerlerini kullanarak kuraklık incelemesi yapmıştır. Akın (2019) Tuz gölü havzasında kuraklık araştırmasını De-Martonne ve Erinç indislerini kullanarak yapmış ve Tuz gölünde giderek artan bir kuraklik olduğunu belirlemiştir.

Trend analizi iklim değişimin etkilerini araştırmak için kullanılan en önemli analizlerden biridir. Türkiye'de ve Dünya'da Mann-Kendall testi ile trend analizi için yağış ve sıcaklık verileri üzerine pek çok çalışma yapılmıştır (Kadıoğlu, 1997; Partal ve Kahya, 2006; Westra ve ark., 2013; Gocic ve Trajkovic 2013). Bu çalışmalar gözlenmiş veriler üzerine trend analizi yapmayı kapsamaktadır. Zhang ve ark. (2009) yaptıkları çalışmada Standart yağış indeksi ve Aridity indeksinin sınıf aralıklarının üzerine MannKendall yöntemi ile trend analizini uygulamışlardır. Bu çalışmayla Kuru ve yağışlı olarak sınıflandırdıkları ayların sayısının yıllar boyunca değişiminini belirlemişlerdir.

$\mathrm{Bu}$ çalışmada, Orta Ve Doğu Karadeniz Bölgesinde bulunan illerdeki istasyonlara ait yağıŞ ve sıcaklık verilerinin SYİ ve De Martonne kuraklık indis değerleri hesaplanmış olup bu değerler üzerinden Mann-Kendall yöntemi ile trend analizleri incelenmiştir. Trend analizleri ile elde edilen sonuçlar karşılaştırılmıştır. Aylık kuraklık indislerinin kuraklık sınıflarına göre sayılarının üzerine trend analizi yapılarak kuraklığın zamanla değişimi belirlenmeye çalışılmıştır.

\section{Materyal ve Metot}

$\mathrm{Bu}$ çalışmada yer alan Karadeniz Bölgesi, Türkiye üzerinde $40^{\circ}-42^{\circ}$ Kuzey paralelleri ile $30^{\circ}-42,5^{\circ}$ Doğu meridyenleri arasında yer alır. $\mathrm{Bu}$ bölgede Karadeniz iklimi etkilidir. Her mevsimde yağış görülür. Yıllık sıcaklık farkları azdır ve yazları serin, kışları ise 1lıktır. Türkiye'de en fazla yağış alan Karadeniz Bölgesi'dir.

Karadeniz Bölgesi'nde dağların kıyı kesimindeki nemli havanın iç kısımlara geçmesi engellediği için kıyı kesim ile iç kesim arasında önemli farklar görülür. İç kısımlarda karasallık nedeniyle yazlar sıcak, kışlar soğuk ve kar yağışlıdır. Dağların yükselti ve doğrultusu nedeniyle Orta Karadeniz Bölümü'nde karadeniz ikliminin yayılma alanı diğer bölümlere göre daha geniștir. Bunun nedeni Orta Karadeniz Bölümü'nde dağlar iç kısımlardan başlamıștır. Bu nedenle Orta Karadeniz Bölümü'nde yağıș miktarında azalma görülür. Doğu Karadeniz Bölümü'ne doğru yağıș miktarlarında artıș görülür. Karadeniz Bölgesi haritası ve kullanılan istasyonların dağılımı Şekil 1'de gösterilmiştir.

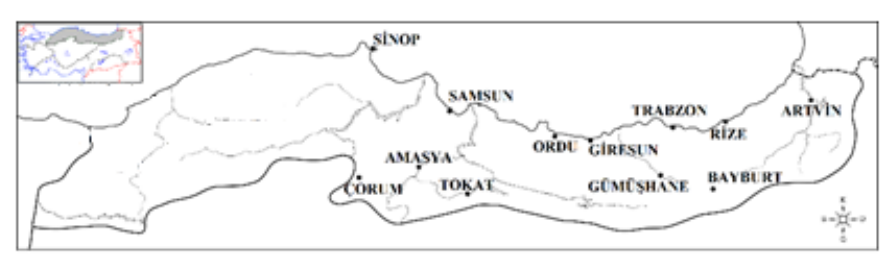

Şekil1. Seçilen İstasyonlar 
Tablo 1. İstasyonlara ait bazı bilgiler

\begin{tabular}{lccccc}
\hline İstasyon Adı & $\begin{array}{c}\text { İstasyon } \\
\text { No }\end{array}$ & Veri Aralığı & $\begin{array}{c}\text { Aylık } \\
\text { Ortalama } \\
\text { Sicaklık } \\
\left({ }^{\circ} \mathbf{C}\right)\end{array}$ & $\begin{array}{c}\text { Yıllık Toplam } \\
\text { Yağışların } \\
\text { Ortalaması } \\
(\mathbf{m m})\end{array}$ & Enlem - Boylam \\
\hline Amasya & 17085 & $1961-2015$ & 13.7 & 459.54 & $40^{\circ} 40^{\prime} \mathrm{K}-35^{\circ} 50 \mathrm{D}$ \\
Artvin & 17045 & $1960-2015$ & 12.2 & 710.10 & $41^{\circ} 10^{\prime} \mathrm{K}-41^{\circ} 49^{\prime} \mathrm{D}$ \\
Bayburt & 17089 & $1960-2015$ & 7.0 & 438.21 & $40^{\circ} 15^{\prime} \mathrm{K}-40^{\circ} 13^{\prime} \mathrm{D}$ \\
Çorum & 17084 & $1960-2015$ & 10.7 & 442.00 & $40^{\circ} 32^{\prime} \mathrm{K}-34^{\circ} 56^{\prime} \mathrm{D}$ \\
Giresun & 17034 & $1960-2015$ & 14.6 & 1259.60 & $40^{\circ} 55^{\prime} \mathrm{K}-38^{\circ} 23^{\prime} \mathrm{D}$ \\
Gümüşhane & 17088 & $1965-2015$ & 9.7 & 461.38 & $40^{\circ} 27^{\prime} \mathrm{K}-39^{\circ} 27^{\prime} \mathrm{D}$ \\
Ordu & 17033 & $1963-2015$ & 14.3 & 1032.00 & $40^{\circ} 59^{\prime} \mathrm{K}-37^{\circ} 53^{\prime} \mathrm{D}$ \\
Rize & 17040 & $1960-2015$ & 14.3 & 2236.88 & $41^{\circ} 02^{\prime} \mathrm{K}-40^{\circ} 30^{\prime} \mathrm{D}$ \\
Samsun & 17030 & $1960-2015$ & 14.5 & 706.39 & $41^{\circ} 20^{\prime} \mathrm{K}-36^{\circ} 15^{\prime} \mathrm{D}$ \\
Sinop & 17026 & $1960-2015$ & 14.2 & 686.32 & $42^{\circ} 01^{\prime} \mathrm{K}-35^{\circ} 09^{\prime} \mathrm{D}$ \\
Tokat & 17086 & $1961-2015$ & 12.5 & 432.39 & $40^{\circ} 19^{\prime} \mathrm{K}-36^{\circ} 33^{\prime} \mathrm{D}$ \\
Trabzon & 17037 & $1960-2005$ & 14.6 & 807.22 & $40^{\circ} 59^{\prime} \mathrm{K}-39^{\circ} 45^{\prime} \mathrm{D}$ \\
\hline
\end{tabular}

\section{Standart Yağış İndisi}

Standartlaştırılmış Yağış İndeksi (SYİ) yöntemi ilk olarak Mckee ve ark. (1993) tarafindan ortaya atılmıștır. SYİ esas olarak belirlenen zaman dilimi içinde yağışın ortalamadan olan farkının standart sapmaya bölünmesi ile hesaplanır.

$$
\mathrm{SY} \dot{\mathrm{I}}=\left(\mathrm{X}_{\mathrm{i}}-\mathrm{X}_{\text {ort }}\right) / \sigma
$$

Burada $\mathrm{X}_{\mathrm{i}}$; aylık yağış miktarı, $\mathrm{X}_{\text {ort }}$; uzun süreli aylık yağışların ortalaması, $\sigma$ ise yağış miktarlarının standart sapmasıdır.

Genellikle yağış serileri normal dağılıma uymazlar. Bunun için SYİ değerlerinin normal dağılıma dönüştürülmesi gerekir. $\mathrm{Bu}$ amaçla yağış zaman serilerine çok iyi uyduğu kabul edilen Gamma dağılımı kullanılır. Bunu yapmak için aylık yağış frekansı dağılımına Gamma olasılık yoğunluk fonksiyonu uydurulur. Gamma fonksiyonu aşağıdaki eşitlikle hesaplanır (Kiymaz ve ark., 2011)

$$
\mathrm{g}(\mathrm{x})=1 /\left(\beta^{\wedge} \alpha \Gamma(\alpha)\right) \mathrm{x}^{\wedge}(\alpha-1) \mathrm{e}^{\wedge}(-\mathrm{x} \beta) \mathrm{x} \geq 0
$$

Burada $\alpha>0$ şekil parametresi, $\beta>0$ ölçek parametresi, $\Gamma(\alpha)$ Gama fonksiyonudur. Yine $\alpha$ ve $\beta$ 'nın tahmininde maksimum olasılık çözümlerini kullanılır.

$$
\begin{gathered}
A=\ln (\bar{x})-\frac{\sum \ln (x)}{n} \\
\alpha=\frac{1}{4 A}\left(1+\sqrt{1+\frac{4 A}{3}}\right) \\
\beta=\frac{\bar{x}}{\alpha}
\end{gathered}
$$

Burada, n: yağış gözlemlerinin sayısıdır. Gözlenmiş zaman serileri kullanılarak elde edilen bu parametreler daha sonra herhangi bir ayda gözlenmiş bir değerin toplam olasıllı yoğunluk fonksiyonunu bulmak için kullanılır. Bu durumda toplam olasılık dağılım fonksiyonu aşağıdaki şekilde tanımlanır.

$G(x)=\int_{0}^{x} g(x) d x=\frac{1}{\beta^{\alpha} \Gamma(\alpha)}=\int_{0}^{x} x^{\alpha-1} e^{-x} d x$

Gama fonksiyonu $\mathrm{x}=0$ için tanımsızdır ve yağgş dağılımı sıfır (0) değerler içerebilir; bu durumda 
toplam olasılık dağılımı aşağıdaki şekilde tanımlanır.

$$
\mathrm{H}(\mathrm{x})=\mathrm{q}+(1-\mathrm{q}) \mathrm{G}(\mathrm{x})
$$

$\mathrm{Bu}$ eşitlikte q sıfır değeri için olasılığı ifade eder. Eğer $\mathrm{m}$ herhangi bir yağış serisindeki sıfır (0) değerleri ifade etmek için kullanılırsa, $q=m / n$ olarak tanımlanabilir. Toplam olasılık değeri $\mathrm{H}(\mathrm{x})$, ortalaması sifir (0) ve bir (1) varyans değeri taşıyan, SYİ değerini ifade eden standart normal rastgele değerli $\mathrm{Z}$ değişkenine dönüştürülür. H(x), SYI'nin değeridir (Kömüşçü ve ark., 2002). SYİ yöntemine göre yapılan sınıflandırma Tablo 2 'de verilmiştir.

Tablo 2. SYİ sinıflandırmast

\begin{tabular}{ll}
\hline SYİ Değerleri & Sınıflandırma \\
\hline 2,0 ve üstü & Çok Şiddetli Nemli \\
$1,50-1,99$ aras1 & Şiddetli Nemli \\
$1,00-1,49$ aras1 & Orta Şiddetli Nemli \\
$-0,99-0,99$ arası & Normal \\
$-1,00--1,49$ aras1 & Orta Şiddetli Kurak \\
$-1,50--1,99$ aras1 & Şiddetli Kurak \\
$-2,00$ ve altı & Çok Şiddetli Kurak \\
\hline
\end{tabular}

Standart Yağış İndisi esas itibariyle kurak ve nemli sınıf aralıklarına göre farklı zaman ölçeklerindeki yağışların hangi sınıfa girdiğini belirlemek amacıyla uygulanan bir yöntemdir. Böylece SYİ değerleri ile yapılan bir kuraklık değerlendirmesinde indeksin arka arkaya negatif olduğu periyod kurak dönem olarak tanımlanır (McKee ve ark. 1993). Bu çalışmada ise 1 aylık SYİ değerlerinin zamansal değişimleri araştırılmıştır.

\section{De Martonne Kuraklık İndisi}

De Martonne indisi Y1llı Ortalama Sicaklık ve Yıllık Toplam Yağış değerleri esas alınarak hesaplanır. $\mathrm{Bu}$ formülle yapilan hesaplama sonucu Yıllık Kuraklık İndisi (IDM) değerleri elde edilir (deMartonne, 1926).

$$
I_{D M}=\frac{P}{T+10}
$$

Burada IDM; y1llk De-Martonne kuraklık indisi, $\mathrm{P}$; yıllık toplam yağış $(\mathrm{mm})$ ve $\mathrm{T}$; yıllık ortalama sicaklıktır. De Martonne aylık kuraklık indis değeri ise aşağıdaki formül ile hesaplanır.

$$
I_{M}=\frac{12 P^{\prime}}{T^{\prime}+10}
$$

Burada $\mathrm{I}_{\mathrm{M}}$; aylık kuraklık indisi, $\mathrm{P}^{\prime}$; aylık toplam yağış (mm), T'; aylık ortalama sicaklıktır. Bu formüllerde $T$ ve $T^{\prime}$ değerlerine eklenen +10 değeri, bazı yerlerdeki negatif sıcaklık değerini pozitif yapmak için kullanılan bir katsayıdır.

Buna göre hesaplanan De-Martonne indis değerleri için aşağıdaki sinıflandırma kullanılabilir.

Tablo 3. De Martonne İndisinin sinıflandırılmast

\begin{tabular}{cc}
\hline $\mathbf{I}_{\mathrm{DM}}$ & Sınıf aralığ \\
\hline $\mathrm{I}_{\mathrm{DM}}<5$ & Çok Kurak \\
$5 \leq \mathrm{I}_{\mathrm{DM}}<10$ & Yarı Kurak \\
$10 \leq \mathrm{I}_{\mathrm{DM}}<20$ & Kurak \\
$20 \leq \mathrm{I}_{\mathrm{DM}}<30$ & Yarı Nemli \\
$30 \leq \mathrm{I}_{\mathrm{DM}}<60$ & Nemli \\
$60 \leq \mathrm{I}_{\mathrm{DM}}$ & Çok Nemli \\
\hline
\end{tabular}

\section{De Martonne - Gottmann İndisi}

De Martonne indisinin, Gottmann ile birlikte ilk haline bazı eklemeler ve değişiklikler yapılması ile elde edilmiştir (Akın, 2019). Buna göre aşağıda verilen denklem elde edilmiştir.

$I_{D M G}=\frac{1}{2}\left(\frac{P}{T+10}+\frac{12 P_{d}}{T_{d}}\right)$

Burada I $\mathrm{I}_{\mathrm{DMG}}$; De Martonne-Gottman indisi değeri, $\mathrm{P}_{\mathrm{d}}$; en kurak ayın yağışı, $\mathrm{T}_{\mathrm{d}}$; en kurak ayın ortalama sicaklığıdır.

$\mathrm{Bu}$ denkleme göre y1llık yağış toplamı ve yıllık ortalama sıcaklık değerlerinin dışında en kurak ayın yağış ve sıcaklık değerleri kullanılmıştır. Sinıflandırma yukarıda yer alan Tablo 3'e göre yapilir.

\section{Mann-Kendall testi}


Mann-Kendall testi hidrometeorolojik zaman serilerinin eğilimlerinin belirlenmesinde yaygın olarak kullanılan parametrik olmayan bir testtir. $\mathrm{Bu}$ testte çeşitli zaman serilerinde var olabilecek pozitif veya negatif yöndeki gidişlerin istatistiksel olarak önemini belirtir.

Parametrik olmayan testler değişkenlerin dağılımından etkilenmediği için verilerin değerlerinden ziyade birbirlerine göre küçüklük büyüklük durumları önemlidir. Veri setindeki her bir değerin kendinden önceki değerlerin farkı alınır. Alınan bu değerlere işaret fonksiyonu uygulanır ve elde edilen -1 ve +1 'lerin toplamiyla $\mathrm{S}$ değeri elde edilir.

$$
\begin{aligned}
& S=\sum_{k=1}^{n-1} \sum_{j=k+1}^{n} \operatorname{sgn}\left(x_{j}-x_{k}\right) \\
& \operatorname{sgn}\left(x_{j}-x_{k}\right)=\left\{\begin{aligned}
+1 ; & \left(x_{j}-x_{k}\right)>0 \text { ise } \\
0 ; & \left(x_{j}-x_{k}\right)=0 \text { ise } \\
-1 ; & \left(x_{j}-x_{k}\right)<0 \text { ise }
\end{aligned}\right.
\end{aligned}
$$

$$
\operatorname{Var}(\mathrm{S})=(\mathrm{n}(\mathrm{n}-1)(2 \mathrm{n}+5)) / 18
$$

S'in varyansı yukarıdaki denklem ile hesaplanır. Eğer veriler içerisinde benzer gözlemlerin olması durumunda $t$ eşit olan gözlemlerin sayısını göstermek üzere $S$ 'nin varyansı aşağıdaki denklem kullanılarak hesaplanır.

$\operatorname{Var}(S)=\frac{n(n-1)(2 n+5)-\sum_{t} t(t-1)(2 t+5)}{18}$

$\mathrm{n}>10$ için varyansı belirlenen Mann-Kendall testinin önemli olup olmadığ 1 z standart değişkeni ile belirlenir.

$$
Z=\left\{\begin{array}{c}
\frac{S-1}{\sqrt{\operatorname{Var}(S)}} ; S>0 \\
0 ; S=0 \\
\frac{S+1}{\sqrt{\operatorname{Var}(S)}} ; S<0
\end{array}\right.
$$

Seçilen bir $\alpha$ anlamlllık seviyesinde $\mathrm{z}$ kritik değeri belirlenir. $\mathrm{Bu}$ çalışmada $\alpha=0,05$ olarak seçilmiştir. Standart Normal Dağılım tablosuna göre $\mathrm{Z}_{(\alpha 2)}$ değeri 1,96 olarak okunmuştur. MannKendall testine göre elde edilen $\mathrm{z}$ değeri [$1,96: 1,96]$ aralığında ise istatistiksel olarak anlamlı bir trend yoktur denir. Aksi halde $\mathrm{z}$ nin değerine göre azalan veya artan bir trend olduğu söylenir (Mondal ve ark., 2012).

\section{Bulgular}

\section{Yağış verilerinin trend analizi}

Çalışmada, ilk önce gözlenmiş yağış verilerinin trend analizi yapılmıştır. Tüm istasyonlara ait aylık toplam ve yıllık toplam yağış verilerinin trend analiz sonuçları Tablo 4'de gösterilmiştir. Sonuçlara göre yıllık olarak bakıldığında tüm istasyonlar artış eğilimi göstermiș olmakla birlikte 6 istasyonda (Artvin, Bayburt, Giresun, Ordu, Sinop ve Tokat) istatistiksel önemli $\left(|z|>z_{(\alpha 2)}\right)$ artış trendi belirlenmiştir. Aylık olarak bakıldığında ise özellikle Mart, Eylül ve Ekim aylarında önemli artış eğilimleri vardır. Ekim ayında 5 istasyonda istatistiksel artış trendi bulunmuştur.

\section{Standart yağış indisi üzerine trend analizi}

Kuraklık indisleri için 12 istasyondan alınan yağış değerleri kullanılmıştır. Hesaplama için SPIGenerator isimli program kullanılmıstır. Samsun istasyonu için yağış verilerine Gama Dağılımı yöntemi uygulanarak elde edilen 1 aylık SYİ değerleri bulunmuş olup Şekil 2'de gösterilmiştir.

Tablo 5 de ise 1 aylık SYİ değerlerinin sınıflandırma aralıklarına göre, o yıla ait hesaplanan sınıf aralığına düşen örnek sayısının üzerine Mann-Kendall trend analizi uygulanmıştır. Örnek vermek gerekirse Çok şiddetli kuraklık sınıfı için (-2 ve altı) aylık indis değerlerinin yıl içindeki sayılarının 1960'tan 2015'e değişimi incelendiğinde Ordu ilinde z değeri 2,04 yani istatistiksel önemli artış olarak bulunmuştur. Buna karşın Şiddetli ve Orta şiddetli kuraklıklarda Bayburt ve Trabzon illerinde istatistiksel önemli azalış trendi vardır. Yine Trabzon ve Artvin'de Çok Şiddetli Nemlilik sınıfındaki SYİ değerlerinin sayısında yıllar içerisinde artış trendi olduğu bulunmuştur. Genel olarak bakıldığında Nemlilik sınıfları için tüm istasyonlarda artış eğilimi görülmektedir. Kuraklık sınıfları içinse genel olarak belirli bir eğilim görülmemiştir. 
Tablo 4. Gözlenmiş̧ yağışların Mann-Kendall test sonuçları

\begin{tabular}{|c|c|c|c|c|c|c|c|c|c|c|c|c|c|}
\hline $\begin{array}{l}\text { İstasyon } \\
\text { Adı } \\
\end{array}$ & Ocal & Şubat & Mart & Nisan & Mayı & Haziron & Temmuz & Ă̈ustos & Eylül & Ekim & Kasım & Aralık & $\overline{\text { Yillık }}$ \\
\hline$\overline{A m a}$ & -( & 0.00 & 0.55 & -0.51 & 1.53 & 1.34 & 0.51 & 0.83 & 0.52 & 1.27 & 0.84 & -1.66 & 1.39 \\
\hline Artvin & 0.57 & 0.09 & 1.53 & -0 & 0.53 & -0.06 & 1 & 1.60 & -0.01 & 1.84 & 9 & -0.92 & 2.25 \\
\hline Bayburt & Not & 1.86 & 0.99 & 2.08 & 0.80 & -1.87 & 1.76 & 0.93 & 0.83 & 1.91 & -0.23 & -0.71 & 2.66 \\
\hline Çorum & -0.08 & -1.04 & 0.20 & -0.71 & -0.23 & 0.61 & -0.49 & -0.14 & 0.86 & 1.03 & 0.36 & -1.51 & 0.40 \\
\hline Giresun & -0. & 0.09 & 0.76 & -0.80 & 0.59 & 1.13 & 0.11 & -0.61 & 0.93 & 2.08 & 1.43 & -0.34 & 3.29 \\
\hline Gümüşhane & 0.79 & 1.83 & 1.01 & 0.48 & -0.08 & -0.63 & 1.33 & 0.02 & 1.65 & 1.31 & 0.67 & -2.48 & 1.18 \\
\hline Ordu & 0.82 & 77 & 2.11 & 41 & 0 & 0.23 & -1.08 & -0.5 & 1.04 & 1.26 & 0 & -0.99 & 2.03 \\
\hline Rize & -0.78 & -0.02 & 0.21 & -0.83 & -0.65 & 1.27 & 0.81 & -0.19 & 1.97 & 1.96 & 0.35 & 0.43 & 1.77 \\
\hline Samsun & 0.11 & -0.10 & 0.57 & -1.03 & -0.27 & 0.89 & 1.34 & 0.61 & -0.37 & 0.33 & 0.29 & 0.17 & 1.32 \\
\hline Sinop & -0.14 & 0.44 & 2.42 & -0.49 & -1.24 & 1.05 & 1.48 & -0.85 & 0.19 & 2.17 & 0.44 & 0.89 & 2.18 \\
\hline Tokat & 0.12 & 1.12 & 1.51 & -0.07 & 0.53 & 0.28 & 0.28 & 1.70 & -0.32 & 2.68 & 0.99 & -2.00 & 2.08 \\
\hline Trabzon & 0.55 & 1.24 & 1.18 & 0.72 & 0.41 & 0.03 & 0.34 & 1.16 & 0.20 & 2.12 & 1.14 & 0.11 & 1.04 \\
\hline
\end{tabular}

Tablo 5. 1 aylık SYI için trend analizi

\begin{tabular}{lcccccc}
\hline İstasyon Adı & $\begin{array}{c}\text { Çok Şiddetli } \\
\text { Kuraklık }\end{array}$ & $\begin{array}{c}\text { Şiddetli } \\
\text { Kuraklık }\end{array}$ & $\begin{array}{c}\text { Orta Şiddetli } \\
\text { Kuraklık }\end{array}$ & $\begin{array}{c}\text { Orta Şiddetli } \\
\text { Nemlilik }\end{array}$ & $\begin{array}{c}\text { Şiddetli } \\
\text { Nemlilik }\end{array}$ & $\begin{array}{c}\text { Çok Şiddetli } \\
\text { Nemlilik }\end{array}$ \\
\hline Amasya & $-0,58$ & $-1,39$ & $-1,51$ & 1,44 & 0,39 & 1,61 \\
Artvin & 0,13 & 0,98 & $-1,89$ & 1,73 & $-0,72$ & $\mathbf{2 , 1 7}$ \\
Bayburt & $-0,11$ & $\mathbf{- 2 , 7 1}$ & $\mathbf{- 2 , 0 7}$ & $\mathbf{2 , 0 0}$ & 0,27 & 1,33 \\
Çorum & 0,17 & 1,06 & 0,29 & $-0,49$ & 0,84 & 1,65 \\
Giresun & $-0,71$ & 0,37 & $-0,73$ & 0,75 & $-0,26$ & 0,79 \\
Gümüşhane & $-0,41$ & $-0,56$ & 0,27 & 1,66 & 0,66 & 0,04 \\
Ordu & $\mathbf{2 , 0 4}$ & $-1,19$ & $-1,75$ & 0,79 & $-0,61$ & 0,59 \\
Rize & 0,93 & 0,87 & $-0,41$ & 1,92 & 0,67 & $-0,27$ \\
Samsun & $-0,62$ & 0,14 & $-0,39$ & 0,51 & 0,05 & $-0,14$ \\
Sinop & 0,50 & $-0,19$ & 0,38 & 0,94 & 0,67 & 0,59 \\
Tokat & $-0,46$ & $-1,40$ & $-0,46$ & 1,34 & $-0,36$ & 1,13 \\
Trabzon & 0,16 & $-0,94$ & $\mathbf{- 1 , 9 7}$ & 0,98 & 0,09 & $\mathbf{2 , 1 9}$ \\
\hline
\end{tabular}




\section{Samsun 1 aylık SYi}

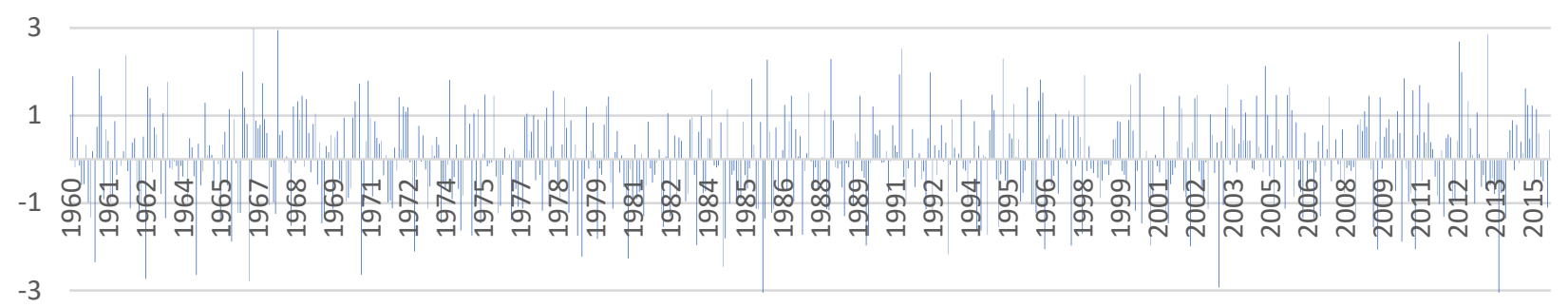

Şekil 2.Samsun 1 aylık SYI değgerleri

\section{De Martonne kuraklık indisinin trend analizi}

Tüm istasyonlar için sıcaklık ve yağış verileri ile aylık olarak De Martonne (DM) kuraklık indis değerleri, yıllık olarak De Martonne Kuraklık indis değerleri ve De Martonne - Gottman (DMG) kuraklık indis değerleri hesaplanmıştır. 17030 numaralı Samsun istasyonundan alınan verilerle hesaplanan aylik De Martonne kuraklık indisleri Şekil 3'te, yıllık De Martonne kuraklık indis değerleri ile De Martonne - Gottman kuraklık indis değerlerinin gidişi ise Şekil 4'te gösterilmektedir. Aylık DM indis değerlerinin 1966-1968 yılları arasında oldukça yüksek değerlere ulaştı̆̆ görülmektedir. DM indisi sinıflandırmasında 20'den küçük olması genellikle o aylar için kuraklığın söz konusu olduğu ve sulama ihtiyacının olduğu anlamında kabul edilmiştir.

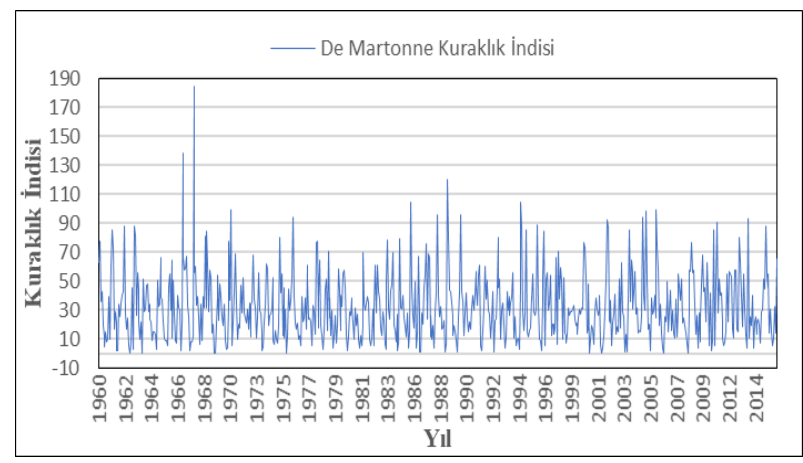

Şekil 3. Aylık DM indisi değerleri (Samsun)

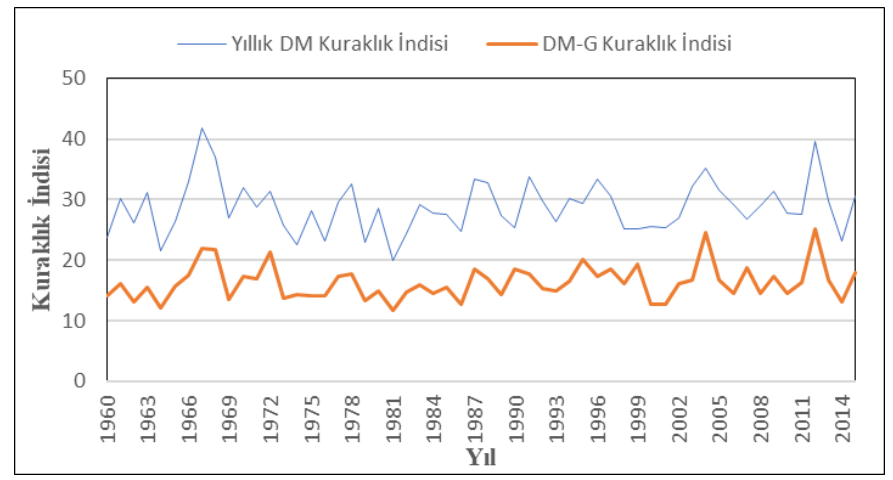

Şekil 4. Yıllık DM ve DM-G indisi de ğerleri (Samsun)

Yillik DM ve DM-G indislerinin karşılaştırılmasında ise $D M-G$ indisinin daha düşük değerler verdiği görülmektedir. Bunun nedeni DM-G indisi hesaplamasinda en kurak aylarında hesaplamaya dahil edilmesidir. Yillık DM indis değerlerine bakıldığında tüm değerlerin 20 'nin üzerinde olduğu görülmektedir. Ancak DM-G indis değerleri 10 ile 30 arasında değişmektedir.

Çalışmanın sonraki aşamasında bu elde edilen aylık DM indis değerleri üzerine Mann-Kendall testi yapılmıştır. Tablo 6'da aylık hesaplanan DM indis değerlerinin ve y1llık hesaplanan DM ve $\mathrm{DM}-\mathrm{G}$ indis değerlerinin üzerine uygulanan Mann-Kendall test sonuçlarını göstermektedir. Aylıklarda özellikle Ekim ayında genel olarak tüm istasyonlarda artış eğiliminde olduğu ve bazı istasyonlarda istatistik olarak önemli artış trendleri (Sinop, Tokat ve Trabzon) olduğu bulunmuştur. Yıllık olarak bakıldığında ise 12 istasyonun 11 tanesi artış eğilimi ve 2 tanesi 
(Giresun, Trabzon) istatistik önemli artıș trendi göstermiştir. DM-G indisi sonuçları ile DM indisi sonuçları arasında bazı istasyonlarda farklılıklar olsa da genel olarak uyumlu olduğu görülmektedir. DM kuraklık indis değerlerinin sinıflandırılmasında $\mathrm{DM}<20$ değeri baz alınarak yıl içindeki kurak dönem gösteren ayların sayısı belirlenmiștir. Uzun dönem yillar içerisinde görülen bu kurak ayların sayılarının trend analizi yapıldığında hesaplanan z değerleri Şekil 5'te harita üzerinde gösterilmiștir. Şekil 5'e göre Rize istasyonu için kurak dönemlerin sayısında artış trendi olması ilginçtir. Tokat istasyonu içinse azalış trendi bulunmuştur $(\mathrm{z}=-2,75)$. Yine Trabzon istasyonu için de $\alpha=0,05$ önem seviyesinde önemli olmasa da ciddi bir azalma eğilimi bulunmuştur $(\mathrm{z}=-1,69)$. Artvin ve Bayburt istasyonları için de azalma eğilimi görülmektedir.

Tablo 6. Aylık ve Ylllık DM ve DM-G indisleri üzerine trend analizi

\begin{tabular}{|c|c|c|c|c|c|c|c|c|c|c|c|c|c|c|}
\hline $\begin{array}{l}\text { İstasyon } \\
\text { Adı }\end{array}$ & Ocak & Şubat & Mart & Nisan & Mayıs & Haziran & Temmuz & Ăgustos & Eylül & Ekim & Kasım & Aralık & $\begin{array}{c}\text { Yillık } \\
\text { DM }\end{array}$ & $\begin{array}{c}\text { Yillık } \\
\text { DM-G }\end{array}$ \\
\hline Amasya & 99 &, 23 & 60 & $-0,52$ & 1,25 & 1,13 & 0,38 & 0,72 & 0,47 & 0,96 & 0,87 & $-1,52$ & 1,17 & 1,33 \\
\hline rtvin & 0,38 & 0,02 & 1,43 & $-0,04$ & 0,46 & $-0,22$ & 1,29 & 1,31 & $-0,09$ & 1,31 & 0,67 & $-0,81$ & 1,80 & 1,56 \\
\hline ayburt & $-0,81$ & 1,56 & $-0,20$ & 161 & 1,00 & -192 & 1,72 & 0,77 & 0,81 & 1,55 & $-0,10$ & 0,16 & 1,40 & 2,08 \\
\hline Çorum & $-0,16$ & $-1,70$ & 0,30 & $-0,85$ & $-0,18$ & 0,47 & $-0,59$ & $-0,24$ & 0,73 & 1,00 & 0,49 & $-1,31$ & 0,17 & 0,02 \\
\hline Gires & 035 & $-0,12$ & 64 & -0 & 04 & 0,97 & 1 & 083 & 0,64 & 1,84 & 1,42 & $-0,15$ & 2,23 & 0,95 \\
\hline Gümüşhane & $-1,25$ & 0,24 & 0,17 & $-0,34$ & $-0,74$ & $-1,43$ & 0,29 & $-0,75$ & 0,58 & $-0,09$ & $-0,02$ & $-2,91$ & $-0,45$ & 0,15 \\
\hline Ord & 0,59 & 0 & 16 & 0,23 & 0 & 00 & 12 & $-0,76$ & 0,77 & 0,93 & 0,76 & $-0,88$ & 0,71 & $-0,54$ \\
\hline Rize & $-0,84$ & $-0,19$ & 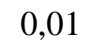 & -0 & $-0,93$ & 1 & 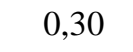 & $-0,52$ & 1,59 & 1,43 & 0,32 & 0,57 & 0,47 & $-1,92$ \\
\hline Samsun & $-0,22$ & $-0,18$ & 0,49 & $-0,88$ & $-0,28$ & 0,64 & 1,30 & 0,50 & $-0,52$ & 0,10 & 0,59 & $-0,18$ & 0,80 & 1,43 \\
\hline 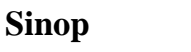 & $-0,26$ & 0,33 & 2,11 & $-0,30$ & $-1,29$ & 0 , & 121 & $-0,98$ & 0,16 & 1,99 & 0,66 & 0,86 & 1,21 & 1,26 \\
\hline Tokat & $-0,38$ & 0,86 & 1,33 & $-0,16$ & 0,41 & 0,04 & 0,22 & 1,51 & $-0,50$ & 2,39 & 1,19 & $-1,60$ & 1,69 & 1,71 \\
\hline Trabzon & 0,53 & 1,29 & 1,27 & 0,64 & 0,36 & $-0,08$ & 0,16 & 1,17 & 0,28 & 2,05 & 1,29 & 0,45 & 3,35 & 2,09 \\
\hline
\end{tabular}

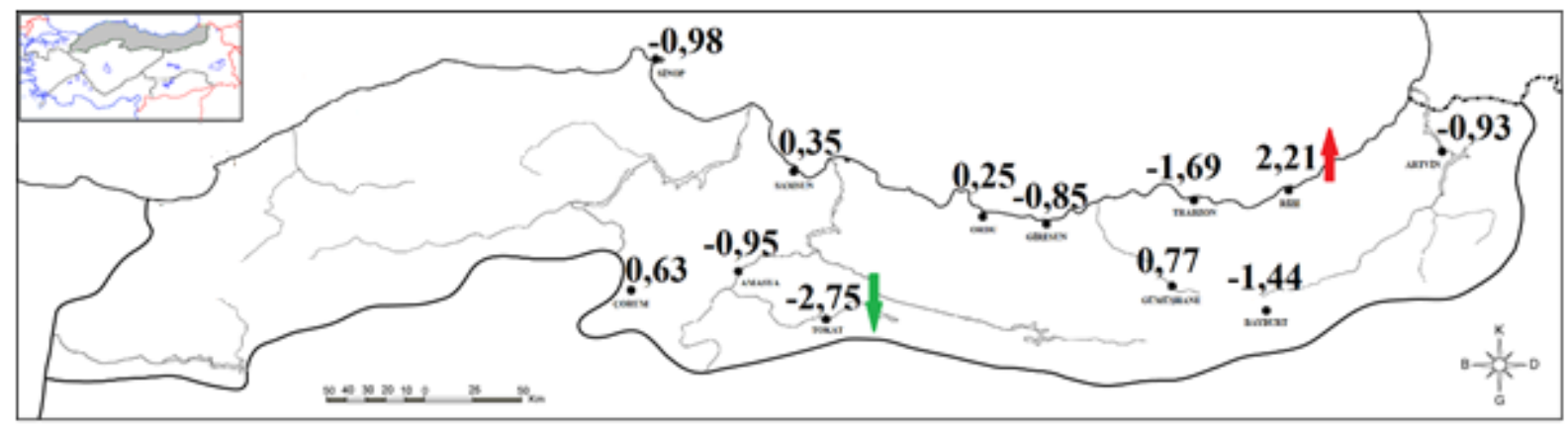

Şekil 5. Aylık DM indisine göre kurak ayların (IDM<20) sayllarının trend analizi 


\section{Sonuçlar}

$\mathrm{Bu}$ çalışmada Orta ve Doğu Karadeniz Bölgesinde bulunan 12 istasyondan alınan yağış ve sicaklık verileri kullanılarak SYİ ve De Martonne kuraklık indisleri hesaplanmış ve Mann-Kendall yöntemi ile trend analizi yapılmıştır. Gözlenmiş veriler üzerine yapılan trend analizine, yıllık toplam yağış verileri tüm istasyonlarda artış eğilimi göstermiş ve 6 istasyonda istatistik olarak önemli artan trend olduğu belirlenmiştir. Aylık olarak bakıldığında ise özellikle Mart, Eylül ve Ekim aylarında önemli artış trendleri olduğu görülmüştür.

1 aylık SYİ değerlerinin sınıflandırma aralıklarına göre yıl içindeki sayılarının 1960'tan 2015'e kadar değişimi incelendiğinde Nemlilik sınıflarında genel olarak tüm istasyonlarda artış eğilimi ve 2 istasyonda (Trabzon ve Artvin) Çok Şiddetli Nemlilik sınıfında istatistik önemli artış trendi olduğu görülmektedir. $\mathrm{DM}$ ve $\mathrm{DM}-\mathrm{G}$ indislerinin trendleri incelendiğinde ise y1llikta ve özellikle Ekim ayında tüm istasyonlarda artış eğilimi görülmektedir. Yıllık olarak bakıldığında 2 istasyonda (Giresun, Trabzon) istatistik önemli artış trendi vardır. Bu sonuç yağış verilerinin trendleri ve 1 aylı SYİ verilerin kuraklık siniflarının trendler ile uyumludur. Aylık DM indislerinin, IDM $<20$ değerleri baz alınarak hesaplanan kurak ayların sayısında ise genellikle karışık bir durum vardır. Bazı istasyonlarda artış bazılarında ise azalış eğimi görülmüştür. Örneğin Rize istasyonu için 0,05 anlamlılık seviyesinde önemli artan trend bulunmuştur. Bu sonuçlara göre Orta ve Doğu Karadeniz bölgesi için genel olarak yağışlarda artış ve kuraklıkta azalış olduğu görülmekle beraber Rize, Samsun ve Çorum gibi bazı istasyonlarda kurak ayların sayısında artış eğilimi olması dikkat çekicidir.

$\mathrm{Bu}$ çalışma bize sadece gözlenmiş yağış verileri değil kuraklık indis değerleri üzerine de trend analizi yapılması halinde iklim değişimi açısından farklı bir bakış açısı elde edilebileceğini göstermektedir.

\section{Kaynaklar}

[1] Akın, B., (2019). Tuz Gölü havzasının kuraklık analizi. Ulusal Çevre bilimleri araştırma dergisi, 2(1), 44-56

[2] Anisfeld, S. C., (2010). Water Resources, Island Press, Washington DC, The United States of America, 2010.
[3] Bonaccorso, B., Bordi, I., Cancelliere, A., Rossi, G., Sutera, A., (2003). Spatial Variability of Drought: An Analysis of the SPI in Sicily, Water Resources Management, 17, 273-296.

[4] Çaldağ, B., Şaylan, L., Toros, H., Sırdaş, S., Bakanoğulları, F., (2004). Drought Analysis in Northwest Turkey, Role of Multipurpose Agriculture in Sustaining Global Environment, 169-179.

[5] de Martonne, E., (1926). Une nouvelle fanction climatologique: l'indice d'aridité, $\quad L a$ Météorologie 2:449-458

[6] Doğan, S., Berktay, A., Singh, V.P., (2012). Comparison of Multi-monthly Rainfall Based Drought Severity Indices, with Application to Semi-arid Konya Closed Basin, Turkey, Journal of Hydrology, 470- 471, 255-268.

[7] Gocic, M., Trajkovic S., (2013). Analysis of changes in meteorological variables using Mann-Kendall and Sen's slope estimator statistical tests in Serbia. Global and Planetary Change, 100, 172-182.

[8] Kadığlu, M., (1997). Trends in Surface Air Temperature Data Over Turkey, International Journal of Climatology 17, 511-520

[9] Keskin, M.E., Terzi, Ö., Taylan, E.D., Yılmaz, A.G., (2007). Isparta Bölgesi Meteorolojik Kuraklık Analizi, I. Türkiye İklim Değişikliği Kongresi-TIKKDEK, 350-359, İstanbul, Türkiye.

[10] Kıymaz, S., Güneş, V., Asar, M., (2011). Standartlaştırılmış Yağış İndeksi İle Seyfe Gölünün Kurak Dönemlerinin Belirlenmesi. GOÜ Ziraat Fakültesi Dergisi, 28(1), 91-102

[11] Kömüşçü, A.Ü., Erkan, A., Turgu, E., (2002). Normalleştirilmiş Yağış İndeksi Metodu (SPI) İle Türkiye'de Kuraklık Oluşum Oranlarının Bölgesel Dağılımı. 3.Atmosfer Bilimleri Sетровуити, 19-21 Mart, 268-275.

[12] McKee, T.B., Doesken N.J., Kleist J., (1993). The relationship of drought frequency and duration to time steps, Preprints, 8th Conference on Applied Climatology, January 17-22 Anaheim, California, 179-184.

[13] Mondal, A., Kundu, S., Mukhopadhyay, A., (2012). Rainfall trend analysis by Mann Kendall test: A case study of NorthEastern part of Cuttack District, Orissa, International Journal of Geology, 2, 70- 78.

[14] Partal, T., Kahya, E., (2006). Trend analysis in Turkish precipitation data, Hydrological 
Processes, 20, 2011-2026.

[15] Petel, N.R., Chopra, P., Dadhwal, V.K. (2007). Analyzing Spatial Patterns of Meteorological Drought Using Standardized Precipitation Index, Meteorological Applications, 14, 329336.

[16] Selçuk, D., (2017). Kızılırmak havzasında hidrometeorolojik parametrelerle kuraklık analizi ve tahmini, Yüksek Lisans tezi. OMÜ Fen bilimleri enstitüsü

[17] Şaylan, L., Durak, M., Şen, O., (1997). Kurakl1k ve Etkileri. Meterolojik Karakterli Doğal Afetler Seтроzуити, Bildiriler Kitab1, 433-444, Ankara.
[18] Topçuoğlu, K., Mengü, G.P., Anaç, S., (2008). Ege Bölgesi Meteorolojik Kuraklık Analizi, 5. Dünya $\mathrm{Su}$ Forumu Türkiye Bölgesel $\mathrm{Su}$ Toplantılar1-Konya Kapalı Havzası Yeraltısuyu ve Kuraklık Konferans1, 175- 184, Konya, Türkiye.

[19] Westra, S., Alexander, L.V., Zwiers, F.W., (2013). Global Increasing Trends in Annual Maximum Daily Precipitation. Journal of Climate, 26. 3904-3918

[20] Zhang Q., Xu C.Y., Zhang Z., (2009). Observed changes of drought/wetness episodes in the Pearl River basin, China, using the standardized precipitation index and aridity index. Theor Appl Climatol 98, 89-99 


\section{Applying trend analysis on drought indices in the Central Black Sea and Eastern Black Sea Region}

\section{Extended Abstract}

Drought is a natural phenomenon, which is be caused by the lack of precipitation for a determined time period. There are four type drought in literature. These are meteorological drought, hydrological drought, agricultural drought and socio-economic drought. Firstly, meteorological drought is begins, then hydrological and agricultural drought follows it (Anisfeld, 2010). This study is focused on meteorological drought, which can be explained by the drought indices such as standardized precipitation index, de-Martonne index, aridity index.

In this study has been carried out to trend analysis on the drought indices obtained in the Central Black Sea and East Black Sea Region In the present study, the Standardized Precipitation Index (SPI) and deMartonne index is used to detect drought months. The drought classifications were determined according to values of SPI for every year. The standardized precipitation index and De Martonne index were obtained using the observed monthly precipitation and temperature data. Then, the MannKendall trend test was applied to the drought indexes. Mann-Kendall test was also used for the observed precipitation data. The data network used in this study consists of monthly precipitation data from 12 stations well spread over the Middle and East Black Sea Region and for a period of 55 years from 1960 to 2015.

According to the Mann-Kendall trend analysis, all of the stations showed increasing trends in the annual total precipitation. For the monthly observed data, the significant increasing trend was also obtained in especially March, September and October months. For standardized precipitation index, there is generally an increasing tendency in Mild Wet, Very Wet and Extreme Wet classifications. Trabzon and Artvin stations showed statistically significant increasing trend for Extreme Wet classification.

Annual DM and DM-G indices showed generally increasing tendency for all the stations. Some significant decreasing trends (in Giresun and Trabzon stations) were also identified in annual DeMartonne indices over the years. Besides, the monthly DM indices showed statistically significant increasing trend in three stations for October month. These results are consistent with the trend results of the observed data and SPI data. However, the trend analysis on the number of drought months according to the DM indices showed some interesting results. There are increasing tendency (positive $z$ value) at the number of drought months in five stations, while there are decreasing tendency (negative $z$ value) at the number of drought months in seven stations.

As the results, there is generally an increase in the precipitations and a decrease in the droughts at Center and Eastern Black Sea Region. However, Rize, Samsun and Çorum stations showed an increasing tendency at the number of drought months.

Keywords: Central and Eastern Black Sea, Standardized Precipitation index, De-Martonne index, Trend Analysis 